\title{
Optimized and Prioritized Test Paths Generation from UML Activity Diagram using Firefly Algorithm
}

\author{
Wasiur Rhmann \\ Department of Computer Science \\ B. B. Ambedkar University \\ ( A Central University) \\ Lucknow, U.P., India
}

\author{
Vipin Saxena \\ Department of Computer Science \\ B. B. Ambedkar University \\ ( A Central University) \\ Lucknow, U.P., India
}

\begin{abstract}
Due to limited resources and challenging time schedule, software testing is usually performed in pressure to assure the fulfilment of the software requirements. Test case generation is a crucial activity of the software testing phase. Testing of all paths from Control Flow Graph is not feasible in software testing, due to limited time and cost. Generation of optimized test paths is a challenging part of the software testing process. In this paper, a new technique to obtain the optimized test paths from activity diagram designed through Unified Modeling Language is demonstrated. A modified algorithm called as Firefly algorithm is used to obtain the critical paths. A case study of air flight check-in is taken as a case study to explain the proposed approach. Paths are prioritized based on Information Flow Metric and their cyclomatic complexity. Obtained optimized paths have no redundancy and produced the better results.
\end{abstract}

\section{Keywords}

Test Case, Information Flow Metric, Firefly algorithm, UML.

\section{INTRODUCTION}

Software testing, a software development activity is used frequently to verify the quality of the software. It can often be a complex and expensive process. With the increasing demand of reliable software, software testing can add upto $50 \%$ of the total software cost. Software companies are oftenly unable to complete testing process due to limited resources and budget constraints which results in poor quality software and unsatisfied users. Software testing is process of executing software with the intent of finding errors [1]. Software testing can be done manually or automatically. Automated software testing is found to be better than manual testing. Sequence of conditions that satisfy certain coverage criteria are called test cases. Test engineer uses test cases to identify whether software system satisfy the predefined requirements. Different models can be used to generate test cases automatically. Test cases generated from these models help to find ambiguities and inconsistencies in the requirement and design of the system. Generated test cases should exercise in such a way that it can provide maximum throughput by uncovering defects. Due to inherent complexity, large systems are difficult to test and large numbers of test cases are required to test these types of the systems. Generation of test cases is difficult step in software testing. So for effective testing, the concept of test prioritization is often applied to run the test cases in order which may reveal faults earlier in the process of testing. Improved fault detection will result in reduction of associated cost and time of software testing. Selection of right test path or test sequence is a challenging part in software testing [2]. The extent to which a property must be tested is determined by test adequacy criteria [3]. Activity diagram describes dynamic aspects of the system. Business and operational workflows of the system can be easily modeled by UML activity diagram. UML based testing has been used by researchers for many years to produce test cases earlier in the development cycle. While prioritization techniques based on code are investigated by most researchers, prioritization of test cases generated from UML diagrams has not been given much attention by researchers so far. Li at et [4] generated test cases from UML activity diagram using the theory of Extenics. It is new discipline to solve contradictory problems. Authors transformed UML activity diagram into directed graph then converted this directed graph into Euler circuit. From Euler circuit authors generated test sequences using Euler circuit algorithm. Although generated test paths are minimized still they contains redundant transitions. Srivastava et al [5] used Cuckoo search for generation of optimized test sequence. Authors used activity diagram for generation of test sequences. They converted activity diagram into Control Flow Graph (CFG). This graph is given as input to cuckoo search algorithm. Static and dynamic weights are assigned to the CFG. Sum of theses weights are calculated to form the value of fitness function. In each iteration, value is optimized to produce better test sequence. Lam et al [6] used artificial bee colony method to generate optimized test suite and independent paths are generated from CFG. Activity diagram results in path explosion due to presence of loop and parallel activities however it is not feasible to consider all paths generated from activity diagram for testing. To address these, few researches have contributed the research papers which are available from literatures [7-9].

Due to easy to use notation and adherence to object-oriented methodology, UML activity diagram has been used as input model for test case generation. The proposed approach generates optimized and prioritized test sequences from activity diagram. This approach uses the Firefly algorithm which is inspired by flashing behaviour of firefly and developed by Yang [10]. Information Flow Metric [11] is applied to the component of the system design. Here nodes of CFG are considered as component. For each node IF value is calculated. The IF value of each node is calculated from the following equation

$\mathrm{IF}(\mathrm{A})=[\mathrm{FANIN}(\mathrm{A}) \times \mathrm{FANOUT}(\mathrm{A})]^{2}$;

where FANIN(A) is number of nodes that call or pass control to node A and FANTOUT(A) is number of nodes called by node A.

The Unified Modeling Language developed by Booch [12] provides graphical tool for modeling and designing software and hardware problems. It is defacto standard of modeling language used for specifying, visualizing and documenting the 
software [13]. Latest UML specification and standard representation are described by OMG [14-15]. Primarily intention of UML is modeling for object-oriented software. Activity diagram provides support for parallel and conditional behaviour for complex sequential activities [16]. Sequences of activities of the system are modeled by activity diagram to describe dynamic behaviour of the system. Activity diagram defined in [17] may contain six tuples

$\mathrm{D}=(\mathrm{W}, \mathrm{JF}, \mathrm{BM}, \mathrm{T}, \mathrm{F}, \mathrm{C})$;

where $\mathrm{W}$ represents the activity, $\mathrm{W}_{0}$ initial activity and $\mathrm{W}_{\mathrm{f}}$ final activity, Fork and Joining of activity are represented by $\mathrm{JF}, \mathrm{T}$ for transition between activity, BM represents branching and merging, $\mathrm{C}$ stands for condition, then

$\mathrm{F} \subseteq(\mathrm{W} \times \mathrm{T} \times \mathrm{C}) \times(\mathrm{T} \times \mathrm{C} \times \mathrm{W})$

Activity diagram can be used for control and object flow modeling, business and operational modeling. In recent years, use of activity diagram has gained attention of researchers for generation of test cases.

\section{FIREFLY ALGORITHM}

Firefly algorithm is a nature inspired technique which is used for solving optimization problems and it simulates the flash pattern and characteristics of fireflies. It is inspired by flashing behaviour of fireflies. Firefly algorithm developed by Xin-She. There are three rules in Firefly algorithm which are described below [18]:

1. Every Firefly can be attracted to other fireflies as they are unisexual;

2. Attractiveness of Firefly is proportional to their brightness. Less brighter Firefly will move toward brighter Firefly and brightness will decrease as distance increases;

3. Brightness of firefly is determined by objective function.

Based on these rules, firefly algorithm can be summarized as the pseudo-code shown in Fig. 1. Two essential components of firefly algorithm are formulation of attractiveness of firefly and variation of light intensity. Attractiveness decreases as distance from source increases. Light intensity can be defined as

$\mathrm{I}\left(\mathrm{r}_{\mathrm{ij}}\right)=\mathrm{I}_{0} \mathrm{e}^{-\gamma \mathrm{r}}{ }_{\mathrm{ij}}^{2}$;

where $\gamma$ is light absorption coefficient, $\mathrm{r}_{\mathrm{ij}}$ is the distance between fireflies $i$ and $j$ are for $x_{i}$ and $x_{j}$ respectively.

Probability of a Firefly i being attracted to another more attractive Firefly $j$ is calculated by

$\Delta \mathrm{x}_{\mathrm{i}}=\beta \mathrm{e}^{-\gamma \mathrm{r} 2}{ }_{\mathrm{ij}}\left(\mathrm{x}_{\mathrm{j}}^{\mathrm{t}}-\mathrm{x}_{\mathrm{i}}^{\mathrm{t}}\right)+\alpha \mathrm{e}_{\mathrm{i}}, \mathrm{x}_{\mathrm{i}}^{\mathrm{t}+1}=\mathrm{x}_{\mathrm{i}}^{\mathrm{t}}+\Delta \mathrm{x}_{\mathrm{i}}$;

where $\mathrm{t}$ is generation number, $\mathrm{e}_{\mathrm{i}}$ is random vector, $\mathrm{a}$ is randomization parameter. The pseudo code of the Firefly algorithm [19] is given below:

Firefly_algorithm()

objective function $\mathrm{f}(\mathrm{x})$, where $\mathrm{x}=\left(\mathrm{x}_{1}, \ldots ., \mathrm{x}_{\mathrm{d}}\right)^{\mathrm{T}}$

initial population of firefly $x_{i}(i=1,2 \ldots \ldots, n)$

brightness of firefly $x_{i}$ is $I_{i}$ determined by $f\left(x_{i}\right)$

light absorption coefficient $\mathrm{v}$ is defined

while $(\mathrm{t}<$ MaxGeneration)

\author{
for $i=1: n$ all $n$ fireflies \\ for $j=1: n$ all $n$ fireflies \\ end if \\ if $\left(I_{i}<I_{j}\right)$, move firefly i towards $j$; \\ vary attractiveness with \\ distance $r$ via $\exp [-\gamma r]$ \\ evaluate new solutions and \\ update light intensity \\ end for $j$ \\ end for $i$ \\ rank the firefly and current \\ global best $g$ is find \\ end while \\ result and visualization
}

\section{PROPOSED METHODOLOGY}

On the basis of above algorithm, the proposed steps are given below for the generation of the test cases from activity diagram:

1. Generate Activity diagram of the given project;

2. Draw Control Flow Graph(CFG) from the Activity diagram;

Control flow graph from Activity diagram is designed with each node represents an activity and control flows of the activities are represented by edges connecting the nodes [20];

3. Convert the Control Flow Graph into Adjacency Matrix;

4. Use Adjacency Matrix to calculate cyclomatic complexity and Information Flow Metric at each node of the CFG

For a given directed graph $\mathrm{G}$ of $\mathrm{n}$ nodes Cyclomatic Complexity is calculated using the following formula:

$v(\mathrm{G})=1+\left(\sum_{i=1}^{n}\right.$ Reduced Outdegree(i) $)$;

where reduced outdegree of a node is one less than the outdegree of that node [21]. Cyclomatic complexity for each node is calculated from adjacency matrix of the CFG. For calculation of cyclomatic complexity of each node, we counted reduced out degree of nodes above the node for which cyclomatic complexity is being calculated and added $1 ;$

5. Use Firefly Algorithm for generation of optimized test paths. For generation of optimized paths, introduced a new matrix decision matrix. Decision matrix is also adjacency matrix whose each node contains a value decided by the formula

$\left.\mathrm{DF}_{\mathrm{i}}=1 /\left[10 \times\left\{\mathrm{CC}_{\mathrm{i}} \times(\mathrm{N}-\mathrm{i})-0.1\right)\right\}\right]$

where $\mathrm{CC}_{\mathrm{i}}$ is cyclomatic complexity of node $\mathrm{i}, \mathrm{N}$ is total number of nodes,

Brightness value is proportional to the decision factor of the nodes;

6. For prioritization of generated test paths, five fireflies are generated at each node of the CFG of the Activity diagram. The brightness of each firefly is determined by the following formula: 
$\mathrm{A}_{\mathrm{i}}=\mathrm{A}_{0} /(1+\gamma \mathrm{d})$

(8)

where $\mathrm{A}_{0}$ is brightness of firefly at node $1 \gamma=\mathrm{IF}_{\mathrm{i}}+\mathrm{CC}_{\mathrm{i}}$

$\mathrm{IF}_{\mathrm{i}}$ and $\mathrm{CC}_{\mathrm{i}}$ are values of Information Flow Metric and cyclomatic complexity at node $\mathrm{i}$

$\mathrm{d}$ is maximum random distance from end node to that node of CFG at which fierflies are deployed and node at the same level have same distances;

7. Mean of brightness of firefly at each node is calculated. Mean of brightness corresponding to each path is calculated. Path with highest mean brightness value will be of high priority.

Now, let us consider a case study of check-in time of Flight whose activity diagram is designed and represented in following Fig 1. In the Fig 1, we have shown different activities of flight check-in process. First passenger goes for obtaining boarding pass. Boarding pass can be obtained either from counter or self-kiosks. If passenger goes on counter and submits Identity and ticket then receives boarding pass otherwise passenger can opt for self-kiosk to receive boarding pass. Here passenger can also select their seat option. After receiving boarding pass, passenger moves for security screening. In the first step of security screening, passenger passes through $\mathrm{x}$-rays counter. If this step is cleared successfully then passenger passes from metal detector. If metal detector screening is also cleared then passenger is authenticated with their biometric identity using Fingerprint. If Fingerprint is also verified then passenger drops baggage at baggage drop counter and goes for their assigned gate [22]. The CFG is created from the activity diagram which is shown below in Fig. 2.

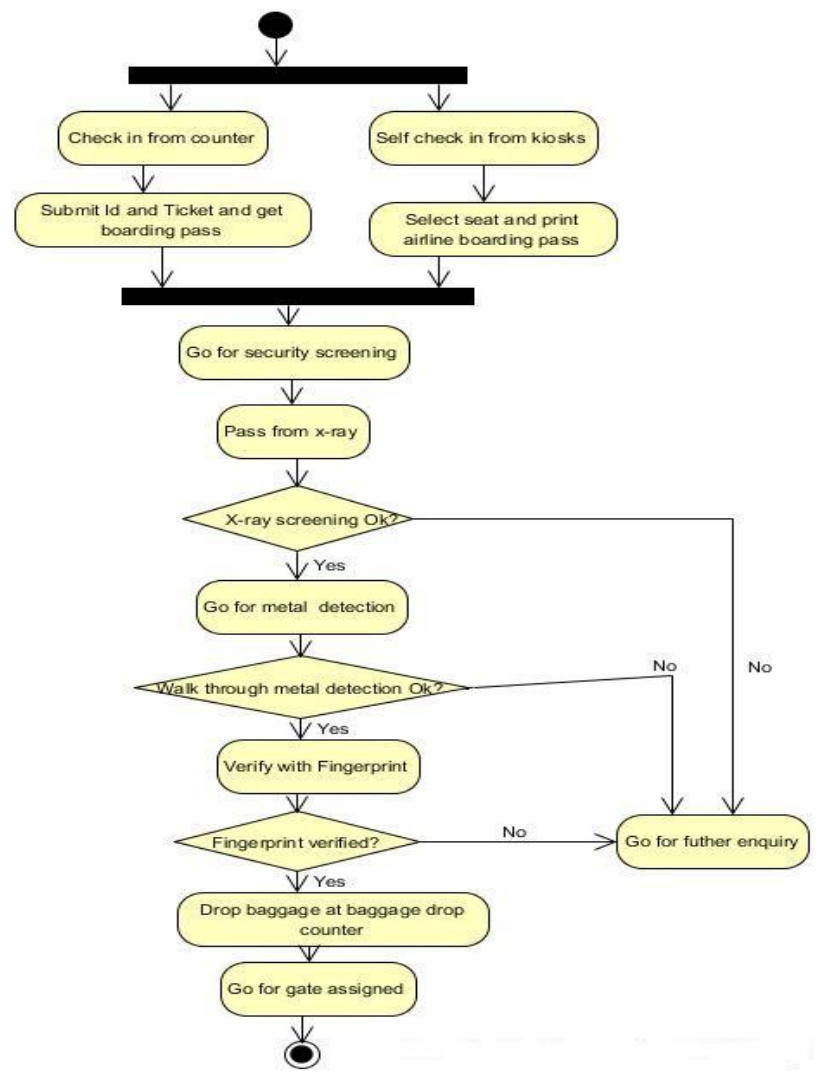

Fig. 1 Activity Diagram for Flight Check-in by Passenger

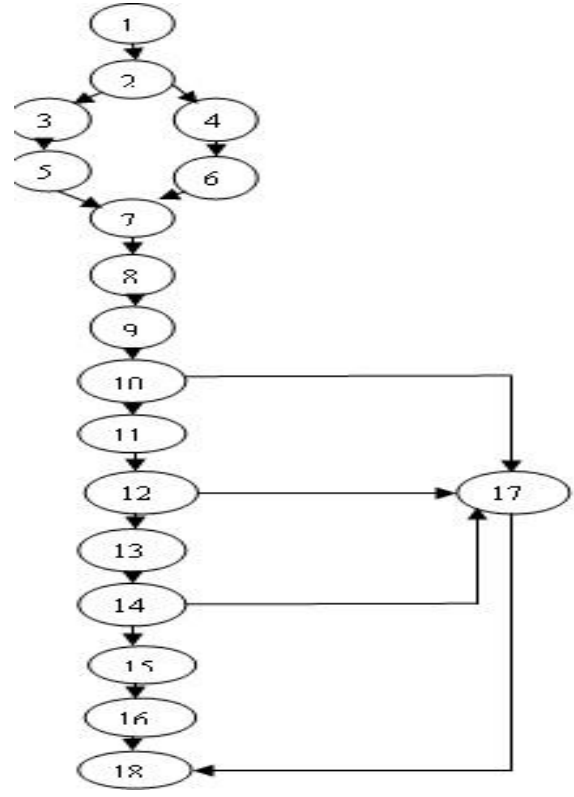

Fig. 2 Control Flow Graph for Flight Check-in Process

Equations (1) and (6) are used to compute Information Flow Metric and Cyclomatic Complexity for each node respectively. From equation (7) decision factor for each node is also computed. The cyclomatic complexity, information flow metric and decision factor of each node are computed and recorded in the table 1 :

Table 1. Cyclomatic Complexity, Information Flow metric and Decision Factor

\begin{tabular}{|c|c|c|c|}
\hline Node & $\begin{array}{l}\text { Cyclomatic } \\
\text { Complexity }\end{array}$ & $\begin{array}{l}\text { Information } \\
\text { Flow Metric }\end{array}$ & $\begin{array}{l}\text { Decision } \\
\text { F actor }\end{array}$ \\
\hline 1 & 5 & 0 & 0001183 \\
\hline 2 & 4 & 4 & 0.00157 \\
\hline 3 & 4 & 1 & 0.00258 \\
\hline 4 & 4 & 1 & 0.00239 \\
\hline 5 & 4 & 1 & 0.00258 \\
\hline 6 & 4 & 1 & 0.00280 \\
\hline 7 & 4 & 4 & 0.00305 \\
\hline 8 & 4 & 1 & 0.00336 \\
\hline 9 & 4 & 1 & 0.00374 \\
\hline 10 & 3 & 4 & 0.00421 \\
\hline 11 & 3 & 1 & 0.00483 \\
\hline 12 & 2 & 4 & 0.00847 \\
\hline 13 & 2 & 1 & 0.01020 \\
\hline 14 & 1 & 4 & 0.02564 \\
\hline 15 & 1 & 1 & 0.034482 \\
\hline 16 & 1 & I & 0.05263 \\
\hline 17 & 1 & 9 & 0.11111 \\
\hline 18 & 1000 & 0 & 0001 \\
\hline
\end{tabular}

Adjacency matrix from CFG is drawn and for each node its outdegree is calculated from sum of number of 1's in each row. 1 is used to represent edge between nodes and 0 for others. It is recorded in the table 2. Decision matrix is used by 
have highest mean brightness value will have highest priority and will be tested first. Similarly other paths will be tested based on their mean of brightness value. From the table it is observed that optimized test path 5 has the highest brightness value and hence having high priority.

Let us compare this with existing research paper written by Jena et al [23]. They presented an approach of test paths generation from UML Activity diagram and generated test cases from Activity flow graph of the activity diagram by traversing the diagram in Depth First Search manner.

\section{Table 5. Test Paths Prioritization}

\begin{tabular}{|c|c|c|}
\hline Test $P$ ath & $\begin{array}{l}\text { Mean of } \\
\text { Brightnes }\end{array}$ & $\begin{array}{c}\text { Priorit } \\
y\end{array}$ \\
\hline $14 \rightarrow 15 \rightarrow 16 \rightarrow 18$ (Test Path 5 ) & 25783 & 1 \\
\hline $\begin{array}{c}1 \rightarrow 2 \rightarrow 4 \rightarrow 6 \rightarrow 7 \rightarrow 8 \rightarrow 9 \rightarrow 10 \rightarrow 17 \rightarrow 1 \\
8 \\
(\text { Test Path } 1)\end{array}$ & 74.45 & 2 \\
\hline $10 \rightarrow 11 \rightarrow 12 \rightarrow 17($ I est Path 3$)$ & 51.658 & 3 \\
\hline $2 \rightarrow 3 \rightarrow 5 \rightarrow 7$ (Test Path 2$)$ & 27989 & 4 \\
\hline $12 \rightarrow 13 \rightarrow 14 \rightarrow 17$ (T est Path 4) & 219012 & 5 \\
\hline
\end{tabular}

The test paths generated using their approaches for the above example are as follows:

Path 1: 1-2-4-6-7-8-9-10-17-18

Path 2: 1-2-3-5-7-8-9-10-11-12-13-14-15-16-18

Path 3: 1-2-4-6-7-8-9-10-11-12-17-18

Path 4: 1-2-4-6-7-8-9-10-11-12-13-14-17-18

Path 5: 1-2-4-6-7-8-9-10-11-12-13-14-15-16-18

The test paths generated from their approach have redundancies. Redundant path will cost more time and efforts. The path 1 is same as path generated from our approach but other paths contains redundancies like 1-2-4-6-7 is repeated in path 3,4 and 5 . Their approach covers activity path coverage criteria however presented our technique also covers activity path coverage criteria while removing the redundant edges. It is shown in figure 6 .

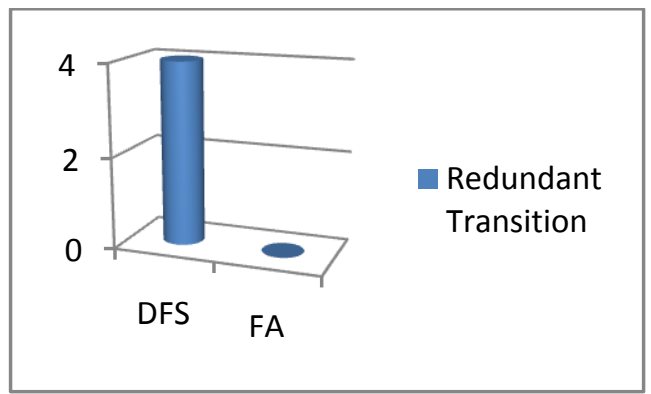

Fig. 6. Firefly approach vs Jena [23] approach

\section{CONCLUSIONS}

In software testing, testing all paths of the system are not feasible to test due to resource and time constraints. This paper presents an approach of test path optimization and prioritization generated from UML Activity diagram based on Firefly approach. While most of the test case prioritization techniques [24-25] are code based. The proposed approach is UML model based and suitable for earlier identification of the faults in the software. Test paths generated from Activity diagram have no redundant edges which will reduce the cost and time of software testing by reducing testing efforts. Our approach is based on the complexity of different constructs of the Activity diagram. In the present work, we used cyclomatic complexity and Information flow metric for prioritization of generated test paths. Cyclomatic complexity and information flow metric can be calculated from adjacency metric of the flow graph of Activity graph. In future, research work may include other UML diagrams for prioritization and generation of test cases.

\section{REFERENCES}

[1] Pressman, R. S. 2010. Software Engineering: A Practitioner's Approach, $7^{\text {th }}$ Edition, McGraw-Hill.

[2] Srivastava P. R., Baby, K. and Raghurama, G. 2009. "An approach of optimal path generation using ant colony optimization", In: Proceedings of the TENCON IEEE Region 10 Conference, Singapore, pp.1-6.

[3] Gosh, S., France, R. Braganza, C. and Kawane, N. 2003 , A Andrews and O Pilskalns, "Test adequacy assessment for UML design model testing", In: Proceeding of the international symposium on the software reliabilty engineering, Denver, CO., pp. 332-343.

[4] Li, L., Li, X., He, T. and Xiong, J. 2013. "Extenics based test case generation from UML Activity diagram", Information Technology and Quantitative Management, pp. 1186-1193.

[5] Srivastava, P. R., Sravya, C., Ashima, Kamisetti, S. and Lakshmi, M. 2012. "Test sequence optimization: an intelligent approach via cuckoo search", International Journal of Bio-Inspired Computation, Vol. 4, No. 3.

[6] Lam, S. S. B., Raju, M. L. P., Kiran, U., Ch, S., and Srivastava, P. R. 2012. "Automated Generation of Independent Paths and Test suite Optimization using Artificial Bee Colony", International Conference on Communication Technology and System Design, pp. 191-200.

[7] Mingsong, C., Xiaokang, Q. and Xuandong, L., Mingsong, Q. Xiaokang, and Xuandong, L. 2006 "Automatic test case generation for UML activity diagrams", In 2006 international workshop on Automation of software test, pp. 2-8.

[8] Linzhang, W., Jiesong, Y., Xiaofeng, Y., Jun, H. and Xuandong, L., and Z. Guoliang, Z. 2004. "Generating test cases from UML activity diagram based on gray-box method". In $11^{\text {th }}$ Asia-Pacific Software Engineering Conference (APSEC04), pp. 284-291.

[9] Kumar, D., and Samanta, D. 2009. "A Novel Approach to Generate Test Cases from UML Activity Diagrams", Journal of Object Technology, Vol. 8, No. 3.

[10] Yang, X. Y. 2009. "Firefly algorithms for multimodal optimization, Stochastic Algorithm: Foundations and Applications", SAGA, Lecture Notes in Computer Science, pp. 169-178. 
[11] Jalote, P. 2005. An Integrated Approach to Software Engineering, $3^{\text {rd }}$ edition, Springer, 2005.

[12] Booch, G. 1994. Object Oriented Analysis and Design with Applications, 2nd edition, Addison Wesley.

[13] Booch, G., Rambaugh, J., and Jacobson, I. 1998. "The Unified Modeling Language User Guide”, Object Technology Series, Addison-Wesley Longman, Inc, 1998.

[14] OMG, Unified Modeling Language Specification, 2011, available online via http://www.omg.org.

[15] OMG, OMG XML Metadata Interchange (XMI) Specification, available online via http://omg.org.

[16] Kansomkeat, S., and Thiket, P. 2010. "Generating Test Cases from UML Activity Diagram using ConditionClassification Tree Method", International Conference on Software Technology and Engineering, IEEE.

[17] $\mathrm{Mu}, \mathrm{K}$., and Gu, M. 2006. "Research on automatic generating test case method based on UML Activity diagram", Journal of Computer Applications, Beijing, Vol. 26, pp. 844-846.

[18] Yang, X. S. 2010. "Firefly algorithms, Levy Flight and Global Optimization", Research and Development in Intelligent System, Springer, pp. 209-218.

[19] Yang, X. S. 2010. "Engineering Optimization: An Introduction with Metaheuristic Applications", John Wiley \& Sons, Inc.

[20] Sabhrawal, S. and Sibal, R., and Sharma, C. 2010. "Prioirtization of Test Case Scenarios Derived from Activity Diagram using Genetic algorithm", International Conference on Computer and Communication Technology.

[21] Jorgensen, P. C. 2014. Software Testing: A Craftsman's Approach, $4^{\text {th }}$ edition, CRC Press, Taylor and Fransis Group.
[22] https://en.wikipedia.org/wiki/Airport_check-in.

[23] Jena, A. K., Swain, S. K., and Mohapatra, D. P. 2014. “A Novel Approach of test case generation from UML Activity diagram", International Conference on Issues and Challenges in Intelligent Computing Techniques, pp. 621-629.

[24] Srikanth, H., 2004. "Requirement based test case prioritization". In: Student research forum at the $12^{\text {th }}$ ACM SIGSOFT international symposium on the foundation of software engineering.

[25] Srikanth, H. and Williams, L. 2005. "On the economics of requirements based test case prioritization". In: Proceeding of the seventh international workshop on economics-driven software engineering research.

\section{APPENDIX}

Table 2. Adjacency Matrix for CFG

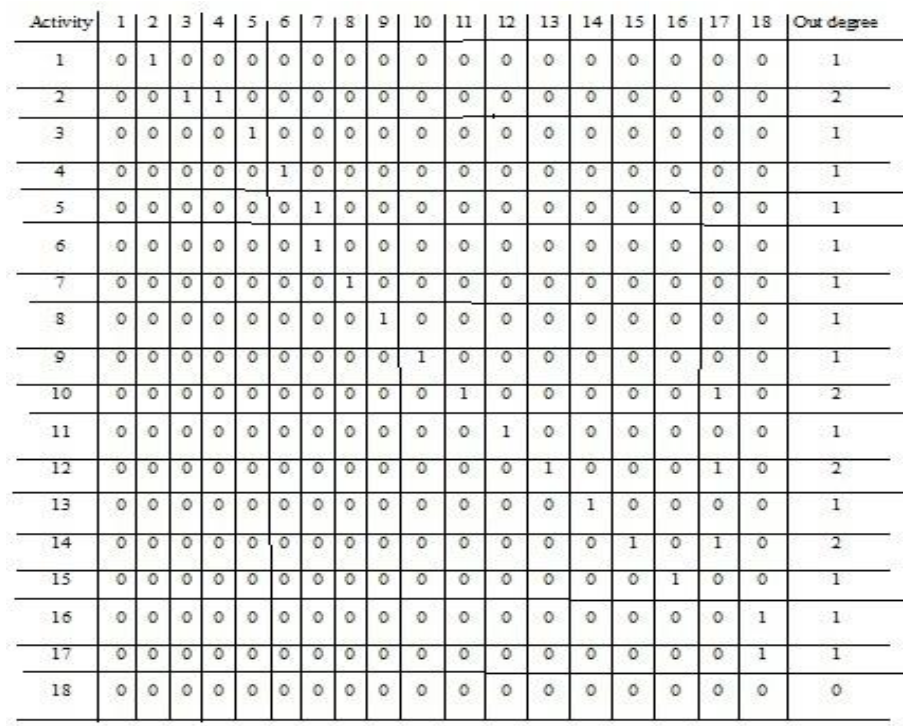

Table 3. Decision Matrix for flight Check-in Process

\begin{tabular}{|c|c|c|c|c|c|c|c|c|c|c|c|c|c|c|c|c|c|c|}
\hline $\begin{array}{c}\text { Activ } \\
\text { ity }\end{array}$ & 1 & 2 & 3 & 4 & 5 & 6 & 7 & 8 & 9 & 10 & 11 & 12 & 13 & 14 & 15 & 16 & 17 & 18 \\
\hline 1 & 0 & $\begin{array}{c}.001 \\
57\end{array}$ & 0 & 0 & 0 & 0 & 0 & 0 & 0 & 0 & 0 & 0 & 0 & 0 & 0 & 0 & 0 & 0 \\
\hline 2 & 0 & 0 & $\begin{array}{l}.00 \\
167\end{array}$ & $\begin{array}{l}.002 \\
39\end{array}$ & 0 & 0 & 0 & 0 & 0 & 0 & 0 & 0 & 0 & 0 & 0 & 0 & 0 & 0 \\
\hline 3 & 0 & 0 & 0 & 0 & $\begin{array}{c}.002 \\
58\end{array}$ & 0 & 0 & 0 & 0 & 0 & 0 & 0 & 0 & 0 & 0 & 0 & 0 & 0 \\
\hline 4 & 0 & 0 & 0 & 0 & 0 & $\begin{array}{c}.002 \\
80\end{array}$ & 0 & 0 & 0 & 0 & 0 & 0 & 0 & 0 & 0 & 0 & 0 & 0 \\
\hline 5 & 0 & 0 & 0 & 0 & 0 & 0 & $\begin{array}{c}.003 \\
05\end{array}$ & 0 & 0 & 0 & 0 & 0 & 0 & 0 & 0 & 0 & 0 & 0 \\
\hline 6 & 0 & 0 & 0 & 0 & 0 & 0 & $\begin{array}{c}.003 \\
05\end{array}$ & 0 & 0 & 0 & 0 & 0 & 0 & 0 & 0 & 0 & 0 & 0 \\
\hline 7 & 0 & 0 & 0 & 0 & 0 & 0 & 0 & $\begin{array}{c}.003 \\
36\end{array}$ & 0 & 0 & 0 & 0 & 0 & 0 & 0 & 0 & 0 & 0 \\
\hline 8 & 0 & 0 & 0 & 0 & 0 & 0 & 0 & 0 & $\begin{array}{c}.003 \\
74\end{array}$ & 0 & 0 & 0 & 0 & 0 & 0 & 0 & 0 & 0 \\
\hline 9 & 0 & 0 & 0 & 0 & 0 & 0 & 0 & 0 & 0 & $\begin{array}{c}.004 \\
21\end{array}$ & 0 & 0 & 0 & 0 & 0 & 0 & 0 & 0 \\
\hline
\end{tabular}




\begin{tabular}{|c|c|c|c|c|c|c|c|c|c|c|c|c|c|c|c|c|c|c|}
\hline 10 & 0 & 0 & 0 & 0 & 0 & 0 & 0 & 0 & 0 & 0 & $\begin{array}{c}.004 \\
83\end{array}$ & 0 & 0 & 0 & 0 & 0 & $\begin{array}{c}.111 \\
11\end{array}$ & 0 \\
\hline 11 & 0 & 0 & 0 & 0 & 0 & 0 & 0 & 0 & 0 & 0 & 0 & $\begin{array}{c}.008 \\
47\end{array}$ & 0 & 0 & 0 & 0 & 0 & 0 \\
\hline 12 & 0 & 0 & 0 & 0 & 0 & 0 & 0 & 0 & 0 & 0 & 0 & 0 & $\begin{array}{l}.01 \\
02\end{array}$ & 0 & 0 & 0 & $\begin{array}{c}.111 \\
11\end{array}$ & 0 \\
\hline 13 & 0 & 0 & 0 & 0 & 0 & 0 & 0 & 0 & 0 & 0 & 0 & 0 & 0 & $\begin{array}{c}.025 \\
64\end{array}$ & 0 & 0 & 0 & 0 \\
\hline 14 & 0 & 0 & 0 & 0 & 0 & 0 & 0 & 0 & 0 & 0 & 0 & 0 & 0 & 0 & $\begin{array}{l}.034 \\
482\end{array}$ & 0 & $\begin{array}{c}.111 \\
11\end{array}$ & 0 \\
\hline 15 & 0 & 0 & 0 & 0 & 0 & 0 & 0 & 0 & 0 & 0 & 0 & 0 & 0 & 0 & 0 & 0 & 0 & 0 \\
\hline 16 & 0 & 0 & 0 & 0 & 0 & 0 & 0 & 0 & 0 & 0 & 0 & 0 & 0 & 0 & 0 & $\begin{array}{c}.052 \\
63\end{array}$ & 0 & $\begin{array}{l}.0 \\
01\end{array}$ \\
\hline 17 & 0 & 0 & 0 & 0 & 0 & 0 & 0 & 0 & 0 & 0 & 0 & 0 & 0 & 0 & 0 & 0 & 0 & $\begin{array}{c}.0 \\
01\end{array}$ \\
\hline 18 & 0 & 0 & 0 & 0 & 0 & 0 & 0 & 0 & 0 & 0 & 0 & 0 & 0 & 0 & 0 & 0 & 0 & 0 \\
\hline
\end{tabular}

Table 4. Calculation of brightness values of fireflies at different node of CFG

\begin{tabular}{|c|c|c|c|c|c|c|c|}
\hline Nod & $\gamma=I F_{i}+C C$ & & \multicolumn{5}{|c|}{$A_{0}=100$} \\
\hline \multirow[t]{2}{*}{1} & 5 & $d_{i}$ & 14.5 & 14.4 & 14.3 & 14.2 & 14.1 \\
\hline & & $\mathbf{A}_{\mathbf{i}}$ & $\begin{array}{c}1.32 \\
1\end{array}$ & 1.36 & 1.37 & 1.38 & 1.39 \\
\hline \multirow[t]{2}{*}{2} & 8 & $d_{i}$ & 13.5 & 13.4 & 13.3 & 13.2 & 13.1 \\
\hline & & $\overline{\mathbf{A}_{\mathbf{i}}}$ & $\begin{array}{c}0.92 \\
5\end{array}$ & $\begin{array}{c}0.93 \\
2\end{array}$ & $\begin{array}{c}0.93 \\
9\end{array}$ & $\begin{array}{c}0.93 \\
8\end{array}$ & $\begin{array}{c}0.94 \\
5\end{array}$ \\
\hline \multirow[t]{2}{*}{3} & 5 & $\mathbf{d}_{\mathrm{i}}$ & 12.5 & 12.4 & 12.3 & 12.2 & 12.1 \\
\hline & & $\overline{\mathbf{A}_{\mathbf{i}}}$ & 1.57 & 1.58 & 1.6 & 1.61 & 1.62 \\
\hline \multirow[t]{2}{*}{4} & 5 & $\mathbf{d}_{\mathrm{i}}$ & 12.5 & 12.4 & 12.3 & 12.2 & 12.1 \\
\hline & & $\overline{\mathbf{A}_{\mathbf{i}}}$ & 1.57 & 1.58 & 1.6 & 1.61 & 1.62 \\
\hline \multirow[t]{2}{*}{5} & 5 & $d_{i}$ & 11.5 & 11.4 & 11.3 & 11.2 & 11.1 \\
\hline & & $\mathbf{A}_{\mathbf{i}}$ & 1.71 & 1.72 & 1.73 & 1.75 & 1.76 \\
\hline \multirow[t]{2}{*}{6} & 5 & $\mathbf{d}_{\mathrm{i}}$ & 11.5 & 11.4 & 11.3 & 11.2 & 11.1 \\
\hline & & $\overline{\mathbf{A}_{\mathbf{i}}}$ & 1.71 & 1.72 & 1.73 & 1.75 & 1.76 \\
\hline \multirow[t]{2}{*}{7} & 8 & $\mathbf{d}_{\mathrm{i}}$ & 10.5 & 10.4 & 10.3 & 10.2 & 10.1 \\
\hline & & $\overline{\mathbf{A}_{\mathbf{i}}}$ & 1.17 & 1.87 & 1.19 & 1.21 & 1.22 \\
\hline \multirow[t]{2}{*}{8} & 8 & $\mathbf{d}_{\mathrm{i}}$ & 9.5 & 9.4 & 9.3 & 9.2 & 9.1 \\
\hline & & $\overline{\mathbf{A}_{\mathbf{i}}}$ & 2.06 & 2.08 & $\begin{array}{c}2.10 \\
5\end{array}$ & 2.12 & 2.15 \\
\hline
\end{tabular}

\begin{tabular}{|c|c|c|c|c|c|c|c|}
\hline \multirow[t]{2}{*}{9} & \multirow[t]{2}{*}{5} & $\mathbf{d}_{\mathrm{i}}$ & 8.5 & 8.4 & 8.3 & 8.2 & 8.1 \\
\hline & & $\mathbf{A}_{\mathbf{i}}$ & 2.29 & 2.32 & 2.35 & 2.38 & 2.41 \\
\hline \multirow[t]{2}{*}{10} & \multirow[t]{2}{*}{7} & $\mathbf{d}_{\mathbf{i}}$ & 7.5 & 7.4 & 7.3 & 7.2 & 7.1 \\
\hline & & $\mathbf{A}_{\mathbf{i}}$ & 1.86 & 1.89 & 1.91 & 1.94 & 1.97 \\
\hline \multirow[t]{2}{*}{11} & \multirow[t]{2}{*}{7} & $\overline{d_{i}}$ & 6.5 & 6.4 & 6.3 & 6.2 & 6.1 \\
\hline & & $\overline{\mathbf{A}_{\mathbf{i}}}$ & 3.7 & $\begin{array}{c}3.75 \\
3\end{array}$ & 3.81 & 3.87 & 3.93 \\
\hline \multirow[t]{2}{*}{12} & \multirow[t]{2}{*}{6} & $\mathbf{d}_{\mathbf{i}}$ & 5.5 & 5.4 & 5.3 & 5.2 & 5.1 \\
\hline & & $\overline{\mathbf{A}_{\mathbf{i}}}$ & 2.94 & 2.99 & 3.04 & $\begin{array}{c}3.10 \\
5\end{array}$ & 3.16 \\
\hline \multirow[t]{2}{*}{13} & \multirow[t]{2}{*}{3} & $\mathbf{d}_{\mathbf{i}}$ & 4.5 & 4.4 & 4.3 & 4.2 & 4.1 \\
\hline & & $\mathbf{A}_{\mathbf{i}}$ & 6.89 & 7.04 & 7.19 & 7.35 & 7.51 \\
\hline \multirow[t]{2}{*}{14} & \multirow[t]{2}{*}{5} & $\mathbf{d}_{\mathbf{i}}$ & 3.5 & 3.4 & 3.3 & 3.2 & 3.1 \\
\hline & & A & 5.4 & 5.55 & 5.71 & 5.88 & 6.06 \\
\hline \multirow[t]{2}{*}{15} & \multirow[t]{2}{*}{2} & $\frac{d_{i}}{}$ & 2.5 & 2.4 & 2.3 & 2.2 & 2.1 \\
\hline & & $\overline{\mathbf{A}_{\mathbf{i}}}$ & $\begin{array}{c}16.6 \\
6\end{array}$ & $\begin{array}{c}17.2 \\
4\end{array}$ & $\begin{array}{c}17.8 \\
5\end{array}$ & $\begin{array}{c}18.5 \\
1\end{array}$ & $\begin{array}{c}19.2 \\
3\end{array}$ \\
\hline \multirow[t]{2}{*}{16} & \multirow[t]{2}{*}{2} & $\mathbf{d}_{\mathbf{i}}$ & 1.5 & 1.4 & 1.3 & 1.2 & 1.1 \\
\hline & & $\overline{\mathbf{A}_{\mathbf{i}}}$ & 25 & $\begin{array}{c}26.3 \\
1\end{array}$ & $\begin{array}{c}27.7 \\
7\end{array}$ & $\begin{array}{c}29.4 \\
1\end{array}$ & $\begin{array}{c}31.2 \\
5\end{array}$ \\
\hline \multirow[t]{2}{*}{17} & \multirow[t]{2}{*}{10} & $\mathbf{d}_{\mathrm{i}}$ & 6.5 & 6.4 & 6.3 & 6.2 & 6.1 \\
\hline & & $\overline{\mathbf{A}_{\mathbf{i}}}$ & 1.51 & 1.53 & 1.56 & 1.58 & 1.61 \\
\hline
\end{tabular}

